\title{
Socrative in the Language Classroom: Tackling Classroom Anxiety and Encouraging Participation
}

\section{Jennifer Wood}

Department of Modern Languages, Prifysgol Aberystwyth University, Wales, UK.

\begin{abstract}
In second language teaching and learning the building of trust relationships and the creation of a mutually supportive atmosphere can be fundamental: It is well recognized that affective concerns, such as anxiety and communication apprehension, are more salient in the language classroom (Hernández \& Rankin, 2015). Practitioners have long been aware of the importance of reducing learner anxiety and one way that has been shown to be effective is motivation (Gardner, 1985). This paper will consider how the use of the smart personal response system Socrative can help address learner anxiety, foster motivation and encourage participation. It will examine theoretical approaches to foreign language anxiety, as well as reviewing motivational factors in language-learning. It will also present qualitative evaluations of using Socrative in the third-level language classroom in both small and larger group settings. The introduction of Socrative has thus far yielded encouraging results, increasing student engagement, promoting interaction, L2 production and more effective learning, alongside a more comprehensive evaluation of student understanding and knowledge retention. As regards its effectiveness in addressing FLA, initial qualitative results suggest that it can be an effective tool in helping to foster a mutually supportive identity and a low-anxiety atmosphere in the classroom.
\end{abstract}

Keywords: Foreign Language Anxiety (FLA); motivation; interaction; trust networks; personal response systems. 


\section{Introduction}

Levels of student stress and anxiety are reportedly on the increase at all levels of education in the UK and is of particular concern to third-level educators, with the number of students declaring a mental health problem having more than doubled in recent years (see Office for Students, 2019; Universities UK, 2018). Not only is this concerning for reasons of general mental health and wellbeing but anxiety has also been shown to have a significant detrimental effect on learning, impairing attention control, information processing, decision latencies, inductive reasoning and memory recall and retention, resulting in situational avoidance, malperformance and non-achievement (Ellis, 1990; Gower, 2004).

Foreign Language Anxiety, or FLA, is considered to be "a distinct complex of selfperceptions, beliefs, feelings, and behaviours related to classroom language learning arising from the uniqueness of the language learning process" (Horwitz, Horwitz \& Cope, 1986, p.128). It is a specific type of anxiety - a situation-specific anxiety - specific to the foreign language-learning context and prompted by a specific set of conditions unique to that context. It can include such things as communication apprehension, test anxiety, social anxiety, performance anxiety, fear of negative evaluation and self-esteem and self-confidence issues. This is of concern to language teachers because it has been shown that language anxiety, according to Krashen (1985), "inhibits the learner's ability to process incoming language and short-circuits the process of acquisition" (cited von Wörde, 2003, p.1). Furthermore, FLA "can interfere with the acquisition, retention and production of the new language" (MacIntyre \& Gardner, 1991, p.86); so FLA can interfere with both the development of language proficiency and students' ability to produce and reproduce the language they have already learned (MacIntyre \& Gardner, 1991). However, some research in this area has shown that a certain level of anxiety can be beneficial or motivational (see Marcos-Llinás \& Garau, p.9596), though one should here distinguish between facilitative and debilitative anxiety. Facilitative anxiety motivates students to learn more, affecting individuals in a positive or excitatory way, whereas debilitative anxiety has a negative or inhibitory effect and impedes learning. Most studies in this area agree that FLA is debilitative and impedes foreign language acquisition and production and therefore has a detrimental impact on student engagement and achievement. Therefore, the alleviation of FLA has important implications for language teaching and learning.

\section{Personal Response Systems (PRS)}

PRS have been in use in an educational context since the 1990s. They allow students to respond to questions via PRS handsets, usually in the form of a wireless TV-style remote control or clicker. For instructors, these response systems can be used to gauge student understanding as well as to identify knowledge gaps or misconceptions. They can also be 
useful for eliciting instant feedback and for encouraging teacher-to-student and student-tostudent interaction, by, for example, opening up a discussion or encouraging students to problem-solve as a group before responding. PRS can also be useful tools for keeping students motivated and engaged as they can be used to switch the focus of a lesson, to bookend or review a topic, or to introduce a different medium to help break up the pace or direction of a class.

For students, PRS help in validating their own learning, progress and understanding. Students can see if they have understood the concepts to which they have been introduced, and they can also gauge where they stand in comparison to their peers, but without being exposed, put on the spot, singled out, or asked to 'perform' in front of the class. For instance, students can receive visual feedback allowing them to see that they are not the only one who does not fully grasp the material. Furthermore, and perhaps more importantly, PRS are fun to use. In my experience, students react to this tool as if it were a game rather than a drill, test or assessment.

Socrative (https://socrative.com), the PRS tool which is the focus of this paper, is a smart personal response system which is freely available online (subscription required for higherlevel features), runs on smart devices and is quick and easy to set up and use.

\subsection{Socrative: Functional Considerations}

Socrative offers a variety of functionalities and activities, including polls, quizzes and quick on-the-fly questions, which can be easily personalized to pedagogical needs. Users can create and deploy activities from a personal bank or import activities shared by other users, and can select from a variety of delivery methods.

For my purposes, I have found that Teacher Paced delivery works best: It offers more control over student responses and provides opportunities for students to measure their performance against their classmates and benefit from guided discussion. The Instant Feedback setting would initially suggest a more user-friendly and less anxiety-inducing option as students can work at their own pace; however, in my experience, it is not as effective as students find it harder to make peer comparisons and teacher guidance is impeded. Teacher Paced delivery provides students with a better sense of their own learning, along with guidance as to where and how to improve, and the teacher with a better sense of the understanding and progress of the entire group. It also allows for more interactivity, particularly if you use a short answer quiz where students can see answers appear on the big screen, in real time, as they post them. Inevitably, as soon as they realise this, they do play with the medium, posting silly answers and cute messages, but I have found it best to engage with this, up to a point. It shows that students are enlivened, engaged and are interacting; they have become autonomous actors within the learning environment. The exercise becomes a game, rather than a grammar drill, for example, and students enjoy being able to post and share messages that everyone can see. 
As regards other functionalities, ensuring students provide and retain an identifying username, which also preserves anonymity, is key. Each activity generates a report enabling tutors to review student and group performance. Having an assigned username helps both tutors to measure performance and students to identify themselves when responding in class or when receiving focused guidance on answers.

\section{Practical Considerations \& Theoretical Context}

In the language classroom, Socrative provides a quick and universal method of assessing student understanding which can be invaluable, especially in larger group settings. Normally, language groups are limited in size. However, as Hernández and Rankin (2015) point out, since the 2008 financial crises "universities are having to do more with less" (p.2), the impact of which on the teaching of lanuguages has been larger class sizes and fewer contact hours, neither of which is ideal. Technology can be mobilised to help address these issues, allowing educators to create more capacity and do more things more quickly and more effectively, but it cannot completely replace other methods, nor should it. Nevertheless, technology can help alleviate some of the current issues and this was initially why I introduced Socrative into my practice at the National University of Ireland, Galway in 2014-15 with the Beginners Spanish cohort of circa 90 students, who came together for a weekly grammar lecture.

I chose PRS as a way to deal with a large-group language class as these systems allow the instructor to test group understanding, not just a few chosen individuals, and to do so rapidly and more comprehensively than traditional, individual Q\&A methods, invaluable when faced with a larger group, particularly in a space not conducive to language learning, such as a lecture theatre. It is also a tool that is less anxiety-inducing, as students are not put on the spot, which helps to build and maintain trust and foster a mutually supportive atmosphere. In second language pedagogy this can be fundamental, as "teaching and learning a language poses unique challenges since, unlike almost all other disciplines, its subject matter is so often also the vehicle of instruction. Thus, it is frequently recognized that in learning languages there are more affective concerns such as anxiety and communication apprehension that are not so salient in other disciplines" (Hernández \& Rankin, 2015, p.1).

As Horwitz et al (1986) say: "Many people find foreign language learning, especially in classroom situations, particularly stressful" (p.125) and this is the case even if they have chosen to study a language. Guiora, in developing the idea of the language ego, argues that language learning is "a profoundly unsettling psychological proposition" because it directly threatens an individual's self-concept and worldview. In part this is because the development of the language ego is considered to directly parallel that of general ego development (Guiora, Brannon \& Dull, 1972, p.422). Therefore, learning a second language means taking on a new identity as learners develop a new mode of thinking, feeling, acting and expressing 
themselves. At the same time, language learners often find themselves unable to express who they are in the L2 because they lack fluency - they are reduced to very basic or infantile forms of expression - which can be threatening not just to self-esteem or status but also to a person's sense of who they are. Horwitz et al (1986) concur, suggesting that any L2 communication entails risk-taking and vulneration: "Because complex and non-spontaneous mental operations are required in order to communicate at all, any performance in the L2 is likely to challenge an individual's self-concept as a competent communicator and lead to reticence, self-consciousness, fear, or even panic" (p.128).

Second language teaching practitioners have long been aware of the importance of reducing learner anxiety and one way that has been shown to be effective is motivation: "positive attitudes and motivation are related to success in second language learning (Gardner, 1985). Motivation is a complex phenomenon, which for second language learners, has been defined (Lightbown \& Spada, 2004) in terms of two factors: 1) learner's communicative needs; 2) their attitudes towards the second language community. If learners want or need to learn the L2 to fulfil professional ambitions or career goals - that is for a particular purpose - they will focus on the communicative value of the L2 and will therefore be motivated to become proficient in it. If learners have a favourable attitude towards the L2 community and/or culture, they will desire more and better contact with them. Gardner and Lambert (1972) coined the terms integrative motivation, to refer to language learning for personal growth and cultural enrichment, and instrumental motivation for language learning for more immediate or pragmatic goals. Other terms that have been used are extrinsic motivation - doing something for its external rewards - and intrinsic motivation - doing something because it makes you feel good or fulfils you. Research has shown that both types of motivation are linked to success in second language learning and that mobilising both types of motivation should be embedded in teaching delivery to truly engage students and achieve deep learning.

In language teaching, there are additional key motivational factors at play in the classroom, not least of which is the social context. People are sensitive to social dynamics and power relationships and "the fact that languages exist in social contexts cannot be overlooked when we seek to understand the variables which affect success in learning." (Lightbown \& Spada, 2004, p.57) This brings us back to the issue of learner anxiety once more, particularly as it has been shown (see Trang, Moni \& Baldauf, 2012, p.9) that despite strong motivational drivers, particularly extrinsic ones, students can still suffer from high levels of FLA which can lead to feelings of low self-esteem, avoidance and withdrawal, including abandonment of language study altogether. Reducing anxiety, on the other hand, seems to increase language acquisition, language retention and learner motivation (von Wörde, 2003, p.12), while enhancing intrinsic motivational drivers as part of this process can help students better manage their anxiety, along with making the language-learning process more enjoyable. 
In the language classroom, what are the situations or activities that cause learners to feel most anxious? Research in this area by Young and von Wörde have shown that oral presentations and oral responses are some of the most anxiety producing activities in the language classroom; this includes when the teacher calls on a student to speak or answer a question. The most anxiety-provoking situation is having to speak or perform in front of others. So it seems that one of the drivers for FLA is the fear of self-exposure. Students, however, feel less anxious when they feel that they are not the only person answering a question, or when they can volunteer rather than being put on the spot or called on to give an answer. Research also shows that students would be more willing to volunteer answers if they were not afraid of saying the wrong thing; that is, they would be less self-conscious if it were commonly understood that everyone makes mistakes. Error-correction is another area that can cause high levels of anxiety, particularly when students are interrupted by an instructor or feel that they are being reprimanded or over-corrected. Nevertheless, studies show that students clearly understand the purpose behind corrections and that they do want their errors corrected.

Tools like Socrative can therefore help alleviate some of the anxieties that learners face in the language classroom because students are not 'put on the spot' as individuals to answer in front of the class, yet they are still asked to provide an answer, not in front of but alongside their peers. The answer is also anonymous, so they can avoid self-exposure. They can see that they are not the only person who makes mistakes, and if they are, well no-one but them (and the teacher) knows, and they can answer and receive the necessary correction, feedback and guidance in a less anxiety-provoking manner.

In general, reducing anxiety in the language classroom comes down to the promotion of certain approaches and methods: a.) The creation of a low-anxiety classroom atmosphere; $b$.) Instructors who are friendly, relaxed and patient and who therefore make students feel comfortable; c.) A classroom where students are encouraged to speak out and to engage but are not constantly being corrected or put on the spot and exposed; d.) Correction that is not harsh and does not spotlight students in front of their peers; and e.) Classes that are interesting and fun - that promote gamification. Saunders and Crookall (cited Young, 1991, p.433) suggest that playing games with and in the language can reduce anxiety as play scenarios provoke less inhibition; social norms are relaxed, destabilized or circumvented and therefore players "can be more easily forgiven for errors of judgement and poor communication." As Young (1991) concludes: "Language games with an emphasis on problem-solving [...] can be an effective way to create interest, motivate students, encourage participation and reduce language anxiety" (p.433). As mentioned, students react to Socrative as if it were a game, reducing the anxiety experienced around assessment, performance and error correction. The other area that students highlight as important in reducing anxiety is the creation of a sense of community or communality - a supportive group identity - or what Terrell called "target language group identification” or Krashen's “club membership”. As von Wörde (2003) 
states: "Anxiety may decrease within the classroom context if students interact in activities that contribute to a feeling of group identity and support" (p.11).

\section{Conclusions}

The introduction of Socrative into my teaching has yielded some interesting and encouraging results. In 2014-15, qualitative observations indicated a marked improvement in student engagement, with students asking to use the tool, becoming more animated and interacting both verbally and via the PRS interface, correcting each other and/or discussing responses. Interactions were largely student-led or student-to-student, not teacher-to-student, promoting a sense of supportive group identity which continued beyond the grammar class: Students became more ready to engage in group activities, volunteer responses and speak out in other language classes which helped develop a low-anxiety classroom atmosphere and encouraged gamification. This was highlighted in feedback questionnaires, where students commented on how much they had enjoyed the grammar classes, how they had experienced improvements in self-confidence and had felt encouraged to continue their language studies. This suggests a reduction in anxiety levels and a mobilisation of key motivational drivers.

As a result, the usage of Socrative and the evaluation of its effectiveness in reducing FLA has been embedded within a wider strategy. For example, during induction workshops in 2018-19 and 2019-20, students were asked to complete the Beliefs About Language Learning Inventory (BALLI), developed by Horwitz (1988), as a springboard for discussions around FLA. Students' responses to certain beliefs (related to self-confidence and self-consciousness in particular) were noted - e.g. B28: I feel self-conscious speaking the foreign language in front of other people where 67\% (2018-19) and 58\% (2019-20) of respondents expressed (strong) agreement - and used as a focus for related discussion, since one way to alleviate anxiety is to acknowledge its existence and share responses. At the end of the academic year, students revisited the BALLI in follow-up workshops and discussed their experiences. Student feedback stressed the value of sharing their concerns and of the approaches taken by different tutors to error correction, noting that they felt less anxious when able to engage without self-exposure via PRS and that it encouraged active participation which had a motivational effect in that it made lessons more engaging and enjoyable. Similar feedback was also received via Module Evaluation Questionaires in 2017-18 and 2018-19 where both language modules in which Socrative was used received $100 \%$ student satisfaction ratings. A further benefit is that the instructor review function also allows for a more comprehensive and effective evaluation of student understanding and knowledge retention, enabling tutors to pinpoint problematic areas and to address them with focused instruction or guidance, making for a more effective classroom, thus facilitating the language acquisition process. 
These qualitative results indicate that the system does increase student engagement and promote interaction and more effective learning. As regards its effectiveness in addressing student anxiety, again initial qualitative results suggest that it can be an effective tool in helping to foster a mutually supportive atmosphere in the classroom while also reducing FLA and increasing motivation, engagement and participation.

\section{References}

Ellis, H. C. (1990). Depressive deficits in memory: Processing initiative and resource allocation. Journal of Experimental Psychology: General, 119(1), 50-62.

Gardner, R (1985). Social Psychology and Second Language Learning: The Role of Attitudes and Motivation. London: Edward Arnold.

Gardner, R. \& Lambert, W. (1972). Attitudes and Motivation in Second-Language Learning. Rowley, Mass.: Newbury House.

Guiora, A., Brannon, R., \& Dull, C. (1972). Empathy and Second Language Learning. Language Learning, 22(1), 111-130. doi.org/10.1111/j.1467-1770.1972.tb00077.x

Gower, P. L. (Ed.). (2004). Psychology of fear. New York: Nova Science.

Hernández, R. \& Rankin, P. (Eds.) (2015). Higher Education and Second Language Learning. Promoting Self-Directed Learning in New Technological and Educational Contexts. Oxford: Peter Lang Ltd.

Horwitz, E. K. (1988). The beliefs about language learning of beginning university foreign language students. The Modern Language Journal, 72, 283-294.

Horwitz, E. K., Horwitz, M. B. \& Cope, J. (1986). Foreign Language Classroom Anxiety. The Modern Language Journal, 70(ii), 125-132.

Krashen, S. (1985). The input hypothesis: Issues and implications. New York: Longman.

Lightbown, P. \& Spada, N (2004). How Languages are Learned. Oxford: OUP.

MacIntyre, P. \& Gardner, R. (1991). Language Anxiety: Its Relationship to Other Anxieties and to Processing in Native and Second Languages. Language Learning, 41(4), 513-534. doi.org/10.1111/j.1467-1770.1991.tb00691.x

Marcos- Llinás, M \& Garau, M. (2009). Effects of Language Anxiety on Three ProficiencyLevel Courses of Spanish as a Foreign Language. Foreign Language Annals, 42(1), 94111. doi.org/10.1111/j.1944-9720.2009.01010.x

Office for Students (OfS). (2019). Mental health. Are all students being properly supported? Retrieved from https://www.officeforstudents.org.uk/media/b3e6669e-5337-4caa-9553049b3e8e7803/insight-brief-mental-health-are-all-students-being-properlysupported.pdf

Trang, T. T. T., Moni, K. \& Baldauf, R. (2012). Foreign language anxiety and its effects on students' determination to study English: to abandon or not to abandon?. TESOL in Context, S3, 1-14. Retrieved from http://tesol.org.au/files/files/271_trang_tran.pdf 
Universities UK. (2018). Minding our future. Starting a conversation about the support of student mental health. Retrieved from https://www.universitiesuk.ac.uk/policy-andanalysis/reports/Documents/2018/minding-our-future-starting-conversation-studentmental-health.pdf

von Wörde, R. (2003). Students' Perspectives on Foreign Language Anxiety. Inquiry, Vol. 8(1), Spring, 1-15.

Young, D. (1991). Creating a Low-Anxiety Classroom Environment: What Does Language Anxiety Research Suggest?. The Modern Language Journal, 75(4), Winter, 426-439.

Young, D. (1990). An Investigation of Students' Perspectives on Anxiety and Speaking. Foreign Language Annals, 23(6), 539-553. 